\title{
Impaired cardiac adrenergic innervation assessed by MIBG imaging as a predictor of treatment response in childhood dilated cardiomyopathy
}

\author{
P Acar, P Merlet, L Iserin, D Bonnet, D Sidi, A Syrota, J Kachaner
}

\begin{abstract}
Objective-To evaluate the prognostic value of metaiodobenzylguanidine (MIBG) imaging in childhood cardiomyopathy.

Design-Prospective cohort study.

Setting-Tertiary referral centre.

Patients-40 children ( 21 boys, 19 girls; mean (SD) age, 7.0 (5.6) years) with heart failure resulting from idiopathic dilated cardiomyopathy $(n=23)$ or various other disorders $(n=17)$. Methods-At the initial examination, cardiac ${ }^{123} \mathrm{I}-\mathrm{MIBG}$ uptake and release, circulating noradrenaline (norepinephrine) concentration, $x$ ray cardiothoracic ratio, and echocardiographic variables were recorded. Cardiac MIBG uptake was obtained by measuring the heart to mediastinum activity ratio on the planar image obtained four hours after MIBG injection. MIBG washout rate was evaluated using relative decrease in cardiac activity measured at 20 minutes and four hours. Patients were treated with angiotensin converting enzyme inhibitors, diuretics, and digitalis, and were followed up for 12 (10) months. Fifteen patients did not respond to medical treatment (12 heart transplants; three deaths), and 25 did respond (improved or stable).

Results-Cardiac MIBG uptake was positively correlated with $x$ ray cardiothoracic index $(r=0.55, \mathrm{p}=0.0008)$ and echocardiographic left ventricular fractional shortening $(r=0.68$, $\mathrm{p}<0.0001)$. Among all the clinical and laboratory variables tested, multivariate discriminant analysis showed that the only independent predictor of an unfavourable outcome was a low MIBG uptake ( $<$ 0.001). Survival curves had a mean threshold value of 1.54 for MIBG uptake. Conclusions-Impaired cardiac adrenergic innervation is strongly related to adverse outcome in children with dilated cardiomyopathy, independently of the aetiology. MIBG imaging may help to stratify risk in such patients.

(Heart 2001;85:692-696)
\end{abstract}

Keywords: noradrenaline; MIBG; single photon imaging; children; cardiomyopathy

Service de Cardiologie Pédiatrique, $\mathrm{CHU}$ Necker-Enfants

Malades, 149 rue de

Sèvres, Paris, France

P Acar

L Iserin

D Bonnet

D Sidi

J Kachaner

Service Hospitalier

Frédéric Joliot,

Département de

Recherche Médicale,

DSV-CEA, 4 place du

Général Leclerc, 91406

Orsay, France

P Merlet

A Syrota

Correspondence to: Dr Merlet

pmerlet@europost.org

Accepted 21 December 2000
Complex and severe neurohormonal system disorders have been reported in adult dilated cardiomyopathies. ${ }^{1-4}$ There are few data on the sympathetic nervous system response to heart failure in children. ${ }^{5}{ }^{123}$ I-metaiodobenzylguanidine (MIBG) imaging provides a means of non-invasively evaluating cardiac adrenergic nerve activity in vivo, as MIBG is subject to the same uptake and storage mechanisms as noradrenaline (norepinephrine). MIBG is internalised by neuronal cells through the uptake-1 system, a transporter and energy dependent system, whereas it enters myocytes through the uptake- 2 system, the activity of which is very low in the human heart. ${ }^{6}$ Cardiac MIBG uptake is dramatically decreased in the failing adult human heart, and there are data indicating that this decrease is related to mortality. ${ }^{7-9}$

The limited availability of cardiac transplantation, with a long waiting list, has increased the importance of accurate and early prognostic evaluation to identify eligible patients. Paediatric cardiologists need better and more objective prognostic indicators than clinical status to determine the indications for heart transplantation. The value of MIBG imaging in childhood cardiomyopathy is at present unknown, and its potential as a prognostic tool has not yet been explored. In this study we examined disorders of the neurohormonal system using MIBG imaging, and evaluated the prognostic value of MIBG in childhood cardiomyopathy.

\section{Methods}

STUDY POPULATION

Forty children, 21 boys and 19 girls (mean (SD) age, 7.0 (5.6) years) entered the study. All had dilated cardiomyopathy with a hypokinetic left ventricle on cross sectional echocardiography (fractional shortening $<30 \%$ ). None had a hypertrophic left ventricle. Cardiomyopathy was idiopathic in 23 patients and had an identifiable cause in the remaining 17 (anthracyclin toxicity in seven, mitochondrial respiratory chain defect in seven, postarrhythmia in two, and postischaemia in one). Before entering the study, all patients had been clinically stable under medical treatment for at least two weeks. No patients included in the study were being treated with drugs known to interact with MIBG uptake such as tricyclic agents or labetolol.

DATA COLLECTION

All data were obtained over an eight day period. 
Radiography

The $x$ ray cardiothoracic ratio was calculated from the maximum cardiac diameter and the intrathoracic diameter at the level of the right costocardiac border. ${ }^{10}$

\section{Echocardiographic data}

Echocardiographic measurements were performed using standard procedures. ${ }^{11}$ End diastolic and end systolic diameters were indexed to the body surface area and the fractional shortening was calculated.

\section{$M I B G$ imaging}

Patients received an intravenous injection of $17.5-74 \mathrm{Mbq}{ }^{123} \mathrm{I}-\mathrm{MIBG}$ (1 Mbq/kg body weight) (CIS BIO-International, Gif sur Yvette, France), after a 30 minute resting period in the supine position. Two 10 minute static acquisitions of the anterior view of the chest were completed, starting at 10 minutes and four hours after the ${ }^{123} \mathrm{I}-\mathrm{MIBG}$ injection, respectively. Cardiac MIBG uptake and release (washout rate) were measured twice by two independent observers, each unaware of the patients' clinical status. Left ventricular activity was recorded using a manually drawn region of interest. Size and positioning were checked on a postero-anterior chest $x$ ray projection. A $5 \times$ 5 to $7 \times 7$ pixel region of interest was placed over the upper mediastinal area (according to the patient's height). The heart to mediastinum (H/M) activity ratio four hours after the MIBG injection was computed to quantify cardiac MIBG uptake, after normalisation for the size of the region of interest.

MIBG washout rate was defined as per cent change in activity $([\mathrm{H}])$ within the left ventricular region of interest from early to delayed images as follows: washout rate $=$ $[\mathrm{H}]$ early $-[\mathrm{H}]$ delayed/ $[\mathrm{H}]$ early ${ }^{\star} 100$, data being corrected for physical decay of ${ }^{123} \mathrm{I}$.

For each patient, the $\mathrm{H} / \mathrm{M}$ and washout rate values were taken as the average of the measurements performed over that patient's scintigraphic image by each observer. The interobserver differences for $\mathrm{H} / \mathrm{M}$ or washout rate measurements were not significant (less than $2 \%$ ). A mean (SD) $\mathrm{H} / \mathrm{M}$ ratio of 2.06 (0.32) (range 1.72-2.84) and a washout rate value of 34 (7)\% (range 19-42\%) were found in healthy young adults (age 20 (2) years, range 18-24 years) in our laboratory.

\section{PLASMA NORADRENALINE DETERMINATION}

Blood samples were obtained after a 30 minute resting period in the supine position. Plasma noradrenaline concentrations were determined by high performance liquid chromatography.

PATIENT MANAGEMENT AND FOLLOW UP

At the time of enrolment in the study, patients' medical treatment included angiotensin converting enzyme (ACE) inhibitors $(90 \%)$, diuretics $(65 \%)$, and digitalis $(40 \%)$. None of the patients were being treated with $\beta$ blockers. No patient was lost to follow up. When clinical status deteriorated, heart transplantation was considered.
DATA ANALYSIS

The clinical status of the patients was determined from their primary physicians and their medical records. Information about the circumstances and causes of death was collected. Analysis of variance was used to compare two subsets of patients - with events and without events. The variables tested as prognostic indicators were: cardiac MIBG uptake, plasma noradrenaline concentration, $x$ ray cardiothoracic ratio, echographic end diastolic and end systolic diameter (both being indexed to body surface area), and echographic fractional shortening. To evaluate these different indices with respect to the clinical outcome, patients who underwent transplantation or who died were included in a single "with events" group $(n=15)$, while survivors $(n=25)$ were included in the "without events" group. The value of variables as predictors of an unfavourable outcome was assessed using univariate and multivariate discriminant analyses. Correlation coefficients, assuming a linear regression, were calculated for paired variables. Data are expressed as mean (SD). The null hypothesis was rejected for $\mathrm{p}<0.05$.

\section{Results}

CLINICAL AND LABORATORY DATA

The mean follow up period was 12 (10) months. During follow up, three patients died from cardiac causes (8\%), 12 underwent heart transplantation (30\%), and 25 who did not receive transplants were alive at the end of the study $(62 \%)$.

Laboratory and demographic data on the whole population are given in table 1. A $19 \%$ decrease in cardiac MIBG uptake (H/M) was found in the patients in comparison with young adult controls $(p<0.001)$. Figure 1 shows two examples of MIBG imaging obtained in patients with severe and moderate heart failure. $\mathrm{H} / \mathrm{M}$ and $x$ ray cardiothoracic index were inversely correlated $(r=-0.55$, $\mathrm{p}=0.0008) . \mathrm{H} / \mathrm{M}$ and echocardiographic left

Table 1 Clinical and laboratory data in the study population

\begin{tabular}{|c|c|}
\hline Variable & $\begin{array}{l}\text { Number of patients or } \\
\text { mean }(S D) \text {, range }\end{array}$ \\
\hline Total population & 40 \\
\hline \multicolumn{2}{|l|}{ Aetiology } \\
\hline Idiopathic & 23 \\
\hline Other causes & 17 \\
\hline Anthracyclin & 7 \\
\hline $\begin{array}{l}\text { Mitochondrial respiratory chain } \\
\text { defect }\end{array}$ & 7 \\
\hline Postarrhythmia & 2 \\
\hline Postischaemia & 1 \\
\hline Age (years) & $\begin{array}{l}7(6), 3 \text { months to } 20 \\
\text { years }\end{array}$ \\
\hline Sex (male/female) & $21 / 19$ \\
\hline Cardiothoracic index (\%) & $57(16)$ \\
\hline $\begin{array}{l}\text { Indexed end diastolic diameter } \\
\left(\mathrm{mm} / \mathrm{m}^{2}\right)\end{array}$ & $67(31), 31-163$ \\
\hline $\begin{array}{l}\text { Indexed end systolic diameter } \\
\left(\mathrm{mm} / \mathrm{m}^{2}\right)\end{array}$ & $56(28), 23-147$ \\
\hline $\begin{array}{l}\text { Echocardiographic fractional } \\
\text { shortening }(\%)\end{array}$ & $17(6), 8-27$ \\
\hline Cardiac MIBG uptake (H/M ratio) & $1.67(0.29), 1.1-2.2$ \\
\hline MIBG washout rate (\%) & $30(11), 10-62$ \\
\hline Plasma noradrenaline $(\mathrm{pg} / \mathrm{ml})$ & 249 (325) \\
\hline Follow up period (months) & $12(10), 1-38$ \\
\hline
\end{tabular}

$\mathrm{H} / \mathrm{M}$ ratio, heart to mediastinum activity ratio 4 hours after MIBG injection. 


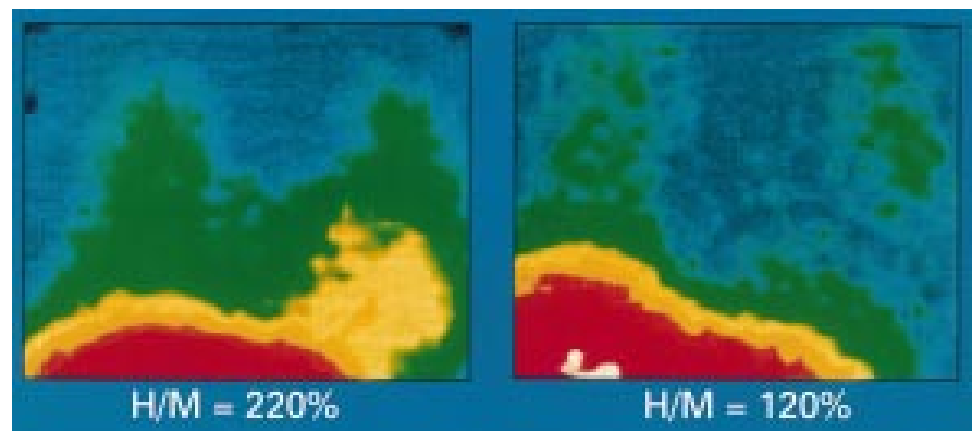

Figure 1 MIBG planar imaging. Cardiac MIBG uptake in two children: one with moderate heart failure (left panel) and one with severe heart failure (right panel). The cardiac MIBG uptake was estimated on the scintigraphic image obtained four hours after the tracer injection, using the activity ratio $(H / M)$ measured within the cardiac and mediastinal areas.

Table 2 Data grouped according to outcome

\begin{tabular}{lll}
\hline Variable & Without events $(n=25)$ & With events $(n=15)$ \\
\hline Age (years) & $6(5), 0.4-14$ & $8(7), 0.5-20$ \\
Sex (male) & $56 \%$ & $46 \%$ \\
Identifiable cause & $44 \%$ & $40 \%$ \\
Cardiothoracic index (\%) & $56(17), 40-70$ & $67(6), 55-77$ \\
Indexed end diastolic diameter $\left(\mathrm{mm} / \mathrm{m}^{2}\right)$ & $62(23), 31-130$ & $75(40), 33-163$ \\
Indexed end systolic diameter $\left(\mathrm{mm} / \mathrm{m}^{2}\right)$ & $50(21), 23-110$ & $65(36), 29-147$ \\
Echographic fractional shortening $(\%)$ & $19(4), 12-27$ & $13(3), 8-18$ \\
Cardiac MIBG uptake $(\mathrm{H} / \mathrm{M} \mathrm{ratio})$ & $1.86(0.17), 1.58-2.2$ & $1.35(0.14), 1.1-1.54$ \\
MIBG washout rate $(\%)$ & $31(10), 11-61$ & $30(13), 10-62$ \\
Noadrenaline concentration $(\mathrm{pg} / \mathrm{ml})$ & $166(77)$ & $308(415)$ \\
Follow up period (months) & $17(9), 6-38$ & $5(3)^{\star}, 1-11$ \\
\hline
\end{tabular}

Unless specified, values are mean (SD), range.

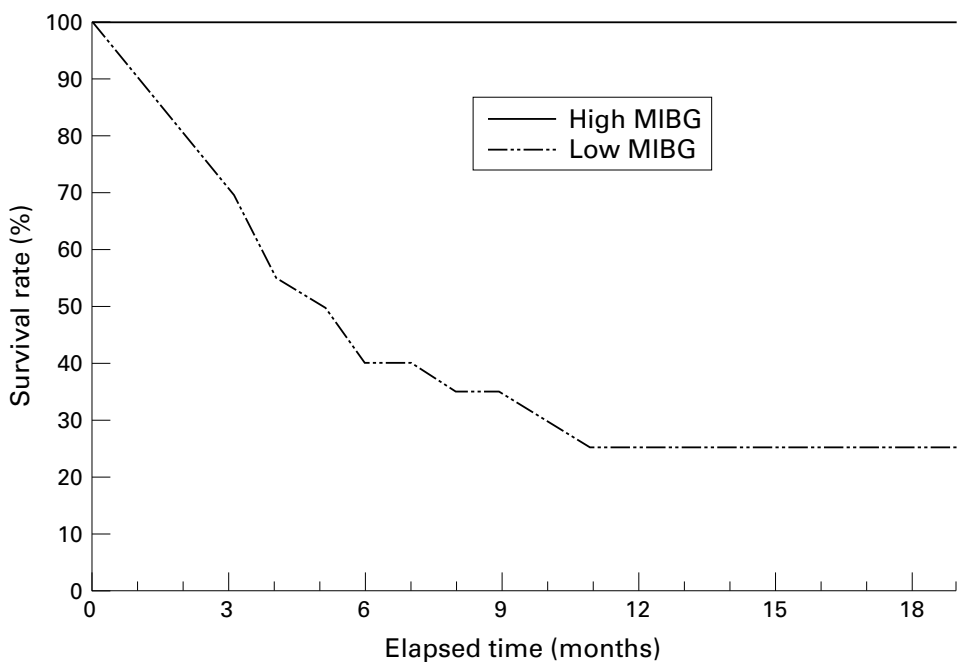

Figure 2 Survival curves obtained from life table analysis in the patient population when using cardiac MIBG uptake to estimate prognosis. MIBG imaging allowed a clear cut distinction to be made between high and low risk subsets when using a threshold ratio of 1.54 for heart to mediastinum activity ratio (H/M). Patients with a low MIBG uptake (dashed line) have a poor prognosis compared with those with a high uptake (solid line).

ventricular fractional shortening were positively correlated $(r=0.68, \mathrm{p}<0.0001) . \mathrm{H} / \mathrm{M}$ was not related to age.

PREDICTION OF RESPONSE TO MEDICAL TREATMENT

Data on the two subsets of patients defined as "without events" and "with events" (death or transplant) are presented in table 2 .

Univariate discriminant analysis showed that among all continuous variables tested (age, identifiable cause, cardiac MIBG uptake and release, plasma noradrenaline concentration, $x$ ray cardiothoracic ratio, $M$ mode echographic data), only $\mathrm{H} / \mathrm{M}(\mathrm{p}<0.0001)$, echographic fractional shortening $(\mathrm{p}<0.001)$, and $x$ ray cardiothoracic ratio $(\mathrm{p}=0.001)$ were predictors of unfavourable outcome. Multivariate discriminant analysis showed that the cardiac MIBG uptake $(p<0.0001)$ was the only independent predictor of unfavourable outcome.

The value of these indices as predictors of adverse outcome was examined using multivariate life table analysis. Survival curves using a threshold value of 1.54 for $\mathrm{H} / \mathrm{M}$ were obtained (fig 2). These curves show that MIBG imaging can distinguish between high risk and low risk patients.

\section{Discussion}

Our data show that MIBG scintigraphy, which explores defects in cardiac sympathetic innervation, is the only independent predictor of unfavourable outcome in childhood dilated cardiomyopathy.

\section{CARDIAC ADRENERGIC INNERVATION IN THE}

FAILING HEART

Adrenergic nerve function and integrity are altered in the failing heart. Cardiac stores of noradrenaline are depleted. ${ }^{12}{ }^{13}$ An increase in noradrenaline release has been found in some studies and a decrease in others. ${ }^{14}{ }^{15}$ Normal fractional extraction of noradrenaline across the failing heart has suggested that uptake-1 function is normal in this situation. ${ }^{16}$ Nevertheless, uptake-1 function has been reported to be diminished in animal models, ${ }^{17-19}$ in tissue obtained from failing human hearts, ${ }^{20-22}$ and in ambulatory patients with heart failure from valvar disease or ischaemic and idiopathic end stage cardiomyopathies. ${ }^{23}{ }^{24}$ Single photon imaging with MIBG or positron emission tomography with ${ }^{11} \mathrm{C}$ hydroxyephedrine have confirmed this decrease in uptake- 1 and noradrenaline storage in the failing human heart. ${ }^{6724}$

Because uptake-1 is the main mechanism involved in terminating the action of the neurotransmitter, its impairment causes an increase in noradrenaline concentration at the myocyte membrane. In explanted hearts from patients with end stage cardiomyopathy, although the global contractile responsiveness to extrinsic noradrenaline was decreased, the relative potency of noradrenaline was increased compared with non-failing hearts, in proportion to the loss of uptake-1 carrier sites. ${ }^{22}$ Impaired uptake-1 function may therefore contribute to adverse effects related to catecholamine overexposure, such as myocyte calcium overload, arrhythmias, increased myocardial oxygen consumption, alteration in coronary artery tone, or $\beta$ adrenergic desensitisation. Evidence for such a mechanism of $\beta$ adrenergic desensitisation has been reported in a dog model of isolated right heart failure, in which the right ventricle showed a selective $\beta$ adrenergic downregulation associated with both noradrenaline tissue depletion and uptake-1 carrier site reduction. ${ }^{25}$ Similarly, the 
right ventricle from subjects with primary pulmonary hypertension shows a selective, chamber specific $\beta$ adrenergic receptor downregulation and a decrease in adrenergic neurotransmitter content. ${ }^{26}$ Finally, tritiated noradrenaline uptake has been found to be directly proportional to $\beta$ receptor density in the left ventricle of patients with end stage dilated cardiomyopathy. ${ }^{27}$

Alternatively, it is possible that raised interstitial noradrenaline concentrations on their own may alter uptake-1 and neuronal noradrenaline storage. Chronic noradrenaline infusion in dogs induces a decrease in noradrenaline uptake associated with lesions of adrenergic nerve terminals; these are very similar to those observed in dogs with heart failure related to rapid ventricular pacing. ${ }^{28}$ Thus decreased MIBG uptake could be an indirect consequence of either chronically increased circulating noradrenaline concentrations or an increase in myocardial noradrenaline release.

Activation of the sympathetic nervous system is a compensatory response involved when pump failure occurs. For this reason-and because the assessment of intrinsic contractility is hindered by the influence of loading variables-measurement of adrenergic nerve function may be a better approach than haemodynamic indices for evaluating heart failure. This may explain why MIBG imaging has been found to be more efficient in predicting prognosis than any of the resting haemodynamic variables in adult idiopathic cardiomyopathy. ${ }^{8}$ Nevertheless the measurement of maximum oxygen consumption has been found to be more potent than MIBG imaging in a selected population of adults suffering from dilated cardiomyopathy (either ischaemic or idiopathic). ${ }^{9}$ As measurement of maximum oxygen consumption is impossible in all but the oldest children, MIBG appears to be a reasonable alternative method of evaluating the severity of the disease.

PROGNOSTIC VALUE OF MIBG IMAGING IN CHILDHOOD DILATED CARDIOMYOPATHY

The natural history in childhood dilated cardiomyopathy remains unclear. Outcome ranges from death to complete recovery. Potential risk factors such as age, ${ }^{29-31}$ arrhythmias, ${ }^{32-34}$ and haemodynamic and histological variables ${ }^{35-39}$ are controversial in childhood cardiomyopathy. Age in our study was not related to prognosis. Although multiple aetiologies caused our study cohort to be heterogeneous, no relation was found between aetiology and prognosis. Among non-invasive indicators such as $x$ ray cardiothoracic ratio and echographic data, cardiac MIBG uptake was the only independent predictor of an unfavourable outcome. An $\mathrm{H} / \mathrm{M}$ value over 1.54 was associated with a good prognosis.

MIBG efflux is accelerated in adult patients with dilated cardiomyopathy, and this is thought to reflect increased cardiac sympathetic nerve activity. No differences in ${ }^{123} \mathrm{I}-$ MIBG scintigraphy pattern were found among patients with heart failure caused by cardiomyopathy or valve disease with volume or pressure overload. ${ }^{40}$ However, our present data and other data from our laboratory are not in accordance with those findings, as MIBG washout was not altered even in patients with severe disease. ${ }^{9}$ The differences may reflect aging or different experimental conditions. Our patients were in hospital during the scintigraphic examination and they were given the MIBG injection only after a 30 minute resting period, according to the standard recommendations for circulating catecholamine measurements. This may have masked potential changes in myocardial MIBG clearance that have previously been observed in adult patients. ${ }^{40}$

\section{CLINICAL IMPLICATIONS}

Our study shows that impairment of sympathetic innervation and functioning is a major predictor of the response to medical treatment in childhood dilated cardiomyopathies, independently of the aetiology. This finding, and the accumulation of evidence indicating that agents which counteract adrenergic hyperactivity decrease mortality and morbidity in adult heart failure, suggest that medical treatment options such as adding $\beta$ blocking agents to ACE inhibitors might be beneficial in childhood cardiomyopathy. ${ }^{41-44}$ Moreover, the present study suggests that the scintigraphic detection of alterations to the sympathetic system in the myocardium could help in selecting candidates for heart transplantation.

1 Cohn JN, Levine BT, Olivari MT, et al. Plasma norepinephrine as a guide to prognosis in patients with chronic congestive heart failure. N Engl f Med 1984;311:819-23.

2 Creager MA, Faxon DP, Halperin JL, et al. The determinants of clinical response and survival in patients with congestive heart failure treated with enalapril. Am Heart $f$ 1982;104:1147-54.

3 Rector TS, Olivari MT, Levine TB, et al. Predicting survival for an individual with congestive heart failure using the plasma norepinephrine concentration. Am Heart $\mathcal{F} 1987$; 114:148-52.

4 Gradman A, Deedwania P, Cody R, et al. Predictors of total mortality and sudden death in mild to moderate heart failmortality and sudden death in mild to $\mathrm{m}$
ure. A Am Coll Cardiol 1989;14:564-70.

5 Ross RD, Daniels SR, Schwartz DC, et al. Plasma norepinephrine levels in infants and children with congestive heart ailure. Am $\mathcal{f}$ Cardiol 1987;59:911-14.

6 Dae MW, De Marco T, Botvinick EH, et al. Scintigraphic assessment of MIBG uptake in globally denervated human and canine hearts-implications for clinical studies. $\mathcal{F} \mathrm{Nucl}$ Med 1992;33:1444-50.

7 Merlet P, Valette H, Dubois Randé JL, et al. Prognostic value of cardiac MIBG imaging in patients with congestive heart failure. F Nucl Med 1992;33:471-7.

8 Merlet P, Benvenuti C, Moyse D, et al. MIBG imaging provides the strongest prognostic information in patients with idiopathic dilated cardiomyopathy. F Nucl Med 1999;40: 917-23.

9 Cohen-Solal A, Esanu Y, Gourgon R, et al. Cardiac metaiodobenzylguanidine (MIBG) uptake in patients with dobenzylguanidine (MIBG) uptake in patients with chronic heart failure. Relationship with pea
prognosis. f Am Coll Cardiol 1999;33:759-66.

10 Glover L, Baxley WA, Dodge HT. A quantitative evaluation of heart size measurements from chest roentgenograms. Circulation 1973;47:1289-96.

11 Sahn DJ, DeMaria A, Kissio J, et al. Recommendations regarding quantitation in M-mode echocardiography: results of a survey of echocardiographic measurements. Circulation 1978;58:1072-83.

12 Chidsey CA, Braunwald E, Morrow AG. Catecholamine excretion and cardiac stores of norepinephrine in congestive heart failure. Am f Med 1965;39:442-51.

13 Shofer J, Tews A, Rühwedel H, et al. Myocardial noradrenaline content: a factor not considered up to now for the prognosis of patients with dilated cardiomyopathy. $Z$ prognosis of patients
Kardiol $1989 ; 78: 366-77$

14 Swedberg K, Viquerat C, Rouleau JL, et al. Comparison of myocardial catecholamine balance in chronic congestive heart failure and in angina pectoris without failure. $A m \mathcal{F}$ Cardiol 1984;54:783-6. 
15 Haskings GJ, Esler MD, Jennings GL, et al. Norepinephrine spillover to plasma in patients with congestive heart failure:
evidence of increased overall and cardiorenal sympathetic evidence of increased overall and cardioren
nervous activity. Circulation 1986;73:615-21.

16 Kaye DM, Lefkovits J, Jenning GL, et al. Adverse consequences of high sympathetic nervous activity in the failing human heart. $\mathcal{F}$ Am Coll Cardiol 1995;26:1257-63.

17 Fisher JE, Horst WD, Kopin IJ. Norepinephrine metabolism in hypertrophied rat heart. Nature 1965;207:951-3.

18 Spann JF, Chidsey CA, Pool PE, et al. Mechanism of norepinephrine depletion in experimental heart failure produced by aortic constriction in the guinea pig. Circ Res 1965;17:312-21.

19 Petch MC, Nayler WG. Uptake of catecholamines by human cardiac muscle in vitro. Br Heart $\mathcal{F} 1979 ; 41: 336-9$.

20 Rose C, Burgess JH, Cousineau D. Tracer norepinephrine kinetics in coronary circulation of patients with heart failure secondary to chronic pressure and volume overload. failure secondary to chronic pry

21 Eisenhofer G, Esler MD, Meredith IT, et al. Sympathetic nervous function in human heart as assessed by cardiac
spillovers of dihydroxyphenylglycol and norepinephrine. spillovers of dihydroxypheny

22 Böhm M, La Rosée K, Schwinge RH, et al. Evidence for reduction of norepinephrine uptake sites in the failing human heart. F Am Coll Cardiol 1995;25:146-53.

23 Eisenhofer G, Friberg P, Rundqvist B, et al. Sympathetic nerve function in congestive heart failure. Circulation 1996 93:1667-76.

24 Ungerer M, Hartmann F, Karoglan M, et al. Regional in vivo and in vitro characterization of autonomic innervation in cardiomyopathic human heart. Circulation 1998;97:17480.

25 Liang CS, Fan T-HM, Sullebarger JT, et al. Decreased adrenergic neuronal uptake activity in experimental right heart failure, 7 Clin Invest 1989;84:1267-75.

26 Bristow MR, Minobe W, Rasmussen R, et al. $\beta$-Adrenergic neuroeffector abnormalities in the failing human heart are produced by local rather than systemic mechanisms. F Clin produced by local rather

27 Beau SL, Saffitz JE. Transmural heterogeneity of norepinephrine in failing human hearts. $\mathcal{F}$ Am Coll Cardiol 1994;23. $579-95$.

28 Himura Y, Felten SY, Kashiki M, et al. Cardiac noradrenergic nerve terminal abnormalities in dogs with experimenta congestive heart failure. Circulation 1993;88:1299-309.

29 Taliercio CP, Seward JB, Driscoll DJ, et al. Idiopathic dilated cardiomyopathy in the young: clinical profile and natural history. F Am Coll Cardiol 1985;6:1126-31.
30 Griffin ML, Hernandez A, Martin TC, et al. Dilated cardiomyopathy in infants and children. 7 Am Coll Cardiol 1988; 11:139-44.

31 Greenwood RD, Nadas AS, Fyler DC. The clinical course of primary myocardial disease in infants and children. $\mathrm{Am}$ Heart f 1976;92:549-60.

32 Chen S, Nouri S, Balfour I, et al. Clinical profile of congestive cardiomyopathy in children. $\mathcal{f} \mathrm{Am}$ Coll Cardiol 1990;15:189-93.

33 Guntheroth WG. Congestive cardiomyopathy in children. 7 Am Coll Cardiol 1990;15:194-5.

34 Friedman RA, Moak JP, Garson A. Clinical course of idiopathic dilated cardiomyopathy in children. $\mathcal{F} \mathrm{Am}$ Coll Cardiol 1991;18:152-6

35 Akagi T, Benson LN, Lightfoot NE, et al. Natural history of dilated cardiomyopathy in children. Am Heart $\mathcal{F}$ 1991;121: 1502-6.

36 Wiles HB, McArthur PD, Taylor AB, et al. Prognostic features of children with idiopathic dilated cardiomyopathy. Am 7 Cardiol 1991;68:1372-6.

37 Harris LC, Rodin AE, Nghiem QX. Idiopathic nonobstructive cardiomyopathy in children. Am $\mathcal{F}$ Cardiol 1968;21: $153-65$

38 Gersony WM. The child with dilated cardiomyopathy: prognostic considerations and management decisions. $\mathcal{f}$ Am Coll Cardiol 1991;18:157-8.

39 Matitiau A, Perez-Atayde A, Sanders SP et al. Infantile dilated cardiomyopathy. Circulation 1994;90:1310-18.

40 Imamura Y, Ando H, Ashihara T, et al. Myocardial adrenergic nervous activity is intensified in patients with heart failure without left ventricular volume or pressure overload. $\mathcal{F}$ Am Coll Cardiol 1996;28:371-5.

41 Pfeffer MA, Braunwald E, Moyé LA, et al. Effects of captopril on mortality and morbidity in patients with left ventricular dysfunction after myocardial infarction: results of the survival and ventricular enlargement trial. $N \mathrm{Engl} F$ Med 1992;327:669-77.

42 Waagstein F, Bristow MR, Swedberg K, et al. Beneficial effects of metoprolol in idiopathic dilated cardiomyopathy. Lancet 1993;342:1441-6.

43 The Cardiac Insufficiency Bisoprolol Study (CIBIS) Investigators. A randomized trial of $\beta$-blockade in heart failure. Circulation 1994;90:1765-73.

44 Packer M, Bristow MR, Cohn JN, et al. Carvedilol Heart Failure Study Group. The effect of carvedilol on morbidity and mortality in patients with chronic heart failure. $\mathrm{N} \mathrm{Engl}$ 7 Med 1996;334:1349-55.

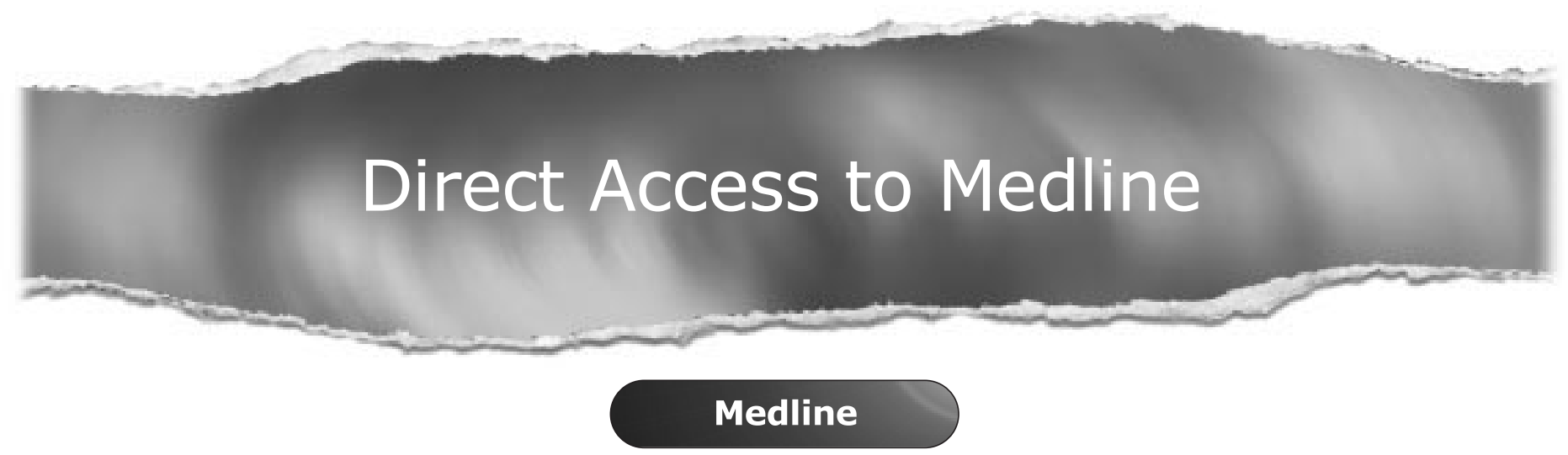

Link to Medline from the homepage and get straight into the National Library of Medicine's premier bibliographic database. Medline allows you to search across 9 million records of bibliographic citations and author abstracts from approximately 3,900 current biomedical journals.

www.heartjnl.com 